\title{
Barriers and Facilitators to Implementation of Digital Solutions
}

\author{
Elaine Bidmead1, Catherine McShane² \\ ${ }^{1}$ NIHR ARC NENC and Centre for Research in Health and Society, Institute of Health, University of Cumbria, Carlisle, Cumbria \\ ${ }^{2}$ County Durham and Darlington NHS Foundation Trust, Darlington Memorial Hospital, Darlington, UK \\ Email: elaine.bidmead@cumbria.ac.uk, catherinemcshane@nhs.net
}

How to cite this paper: Bidmead, E. and McShane, C. (2021) Barriers and Facilitators to Implementation of Digital Solutions. Health, 13, 1330-1345.

https://doi.org/10.4236/health.2021.1311097

Received: October 21, 2021

Accepted: November 22, 2021

Published: November 25, 2021

Copyright $\odot 2021$ by author(s) and Scientific Research Publishing Inc. This work is licensed under the Creative Commons Attribution International License (CC BY 4.0).

http://creativecommons.org/licenses/by/4.0/

\begin{abstract}
Intro/background: The NHS Long term plan calls for "digital-first" solutions, however, many good innovations fail. Barriers to digital innovation in healthcare are well-rehearsed and often predictable. This paper aims to highlight issues to be considered in implementation. Methods: It is a qualitative study of experiences of telehealth implementation. Findings: Staff engagement is crucial to acceptance; compatibility with existing practises helps but where impossible, pathway redesign is necessary. There is a notion that staff of any grade can become digital champions, yet the role is challenging for staff without power. Funding systems can restrict adoption due to associated savings impacting elsewhere in the system. Organisational support for innovation is often apparent but does not trickle down to service level sufficiently. Conclusions: Senior management needs to lead on and support at a micro level the implementation of digitally enabled health care. Funders and commissioners need to recognise that innovation takes time and that measured approaches are more successful.
\end{abstract}

\section{Keywords}

Telehealth, Telemonitoring, Digital Health, Digital Health Adoption, Qualitative Research

\section{Introduction}

The push for digitally enabled healthcare (DEHc) has been apparent for some time; digitalisation has long been seen as a solution to the growing demand for services. Prior to the COVID-19 pandemic, a succession of policy documents had called for digitalisation within the National Health Service (NHS), including the NHS Long Term Plan [1]. The plan envisaged digital transformation of the 
NHS to the extent that within ten years "the existing model of care [will] look markedly different". The plan anticipated a "digital-first" NHS where: "Senior clinicians are supported by digital tools"; patients can be treated at home and monitored via "wearable devices"; people will manage and monitor their own health "guided by digital tools"; GPs will offer online consultations, and so on. However, despite "widespread agreement about the importance and potential benefits" [2] and "much policy-level talk of triggering a revolution in service delivery" [3], digital innovation in health and care proved challenging and many good projects failed to be adopted [2] [3] [4] [5] [6]. The COVID-19 pandemic was a game-changer wherein $\mathrm{DEHc}$ became seen as an appropriate response to restricted access to in-person healthcare provision. Whether previous barriers to the adoption of DEHc have been overcome or whether it is merely perceived as a temporary solution, remains to be seen [7].

This paper aims to elucidate factors that enable and inhibit the introduction, adoption and roll-out of DEHc in hospital settings. We do this by examining clinical stakeholder experiences of introducing the Health Call patient monitoring system into two different services at one NHS foundation Trust (Trust1) prior to the pandemic. Health Call is a flexible, interactive system that generates customised services to monitor patients with long-term conditions or undergoing outpatient treatment. The platform is a product of collaboration between the technology company InHealthcare [8] and Trust1, with funding to develop technology-based services from the Strategic Health Authority (SHA). Its design was informed by patients and clinicians. Engagement with patients revealed patients preferred face-to-face monitoring but when issues about capacity and demand were explained, patients said they wanted to submit results through a range of devices. Clinicians were concerned with safety and data security; they wanted any digital system to be "safe". They also wanted involvement in designing interventions and in informing pathways; clinicians made it clear that they did not want a separate, additional IT system. The resulting system is interoperable with existing clinical systems, allows clinicians to design bespoke pathways, appropriate to both service and patients, and can communicate with patients via automated telephone calls, email, text, app and web portal. In addition, the system does not hold any patient-specific information and only reads the information patients submit.

Health Call was piloted within the INR (International Normalised Ratio) service and the dietetics service at Trust1. The prevailing and digital pathways are summarised in Table 1. Both pilots received positive evaluations wherein Health Call was shown to be an acceptable, safe and effective way to monitor patients. Patients reported high levels of satisfaction with the system; INR patients enjoyed the convenience it offered (including reduced travel/parking expense, reduced time away from work, freedom to go on holiday). Undernutrition patients reported feeling better cared for and having an increased feeling of shared responsibility. Despite demonstrable savings for patients neither evaluation was 
Table 1. Prevailing and digital pathways in the INR and undernutrition services.

\begin{tabular}{ll}
\hline \multicolumn{1}{c}{ INR Service } & \multicolumn{1}{c}{ Undernutrition Service } \\
\hline $\begin{array}{l}\text { Patients taking warfarin require INR } \\
\text { (International Normalised Ratio) }\end{array}$ & $\begin{array}{l}\text { Patients who are at risk of undernutrition } \\
\text { or are undernourished require }\end{array}$ \\
monitoring, this is done by analyzing & monitoring for weight, appetite and \\
blood samples obtained via a finger & compliance with prescribed oral \\
pinprick. The INR service monitors & nutritional supplements (ONS). The \\
$\sim 3700$ patients. & dietetic service monitors $\sim 1000$ patients.
\end{tabular}

\section{Prevailing Pathway}

Most patients attend clinic for testing, others submit samples to clinic through Pharmacies, GP surgeries or District Nurses. Patients also answer basic safety questions (relating to bleeding symptoms, missed Warfarin doses and medication changes). All samples are analysed by INR clinic staff; if the INR reading is out of range, Warfarin doses are adjusted. Patients are then given their next appointment date. The frequency of monitoring is dependent on time with the service

Dieticians visit patients in their own homes or in residential settings. Patient weights are recorded, dietary history assessed, and recommendations made; which may include provision of ONS. Follow-up is arranged at 3-month intervals in line with the pathway; patients usually receive three follow-ups but sometimes more. Patients are followed up in outpatient clinic or in own home. and time within INR range.

\section{Digital Pathway}

\section{Digitally enabled INR self-testing pathway.}

Using a lancet device, patients produce a blood sample which they analyse using a Roche self-monitoring device. Patients then submit the reading and respond to safety questions through an automated phone call or an on-line portal; the data is directly sent to the patient's clinic.

If a response is not received an alert is sent to clinic prompting follow-up by a clinician.

INR readings are analysed using anticoagulation software which calculates the next warfarin dose and test date. If readings are normal, the automated process continues, and the patient is notified via a second message (automated phone call or email). Any irregular readings or adverse answers alert the clinic and direct contact is made with the patient.

\section{Digitally enabled monitoring of patient weight, appetite and compliance with ONS.}

Care homes record and submit information to the dietetic service via a secure web portal. Patients resident in their own homes receive an automated phone call asking for responses to questions about appetite and compliance and to enter their weight.

If a response is not received an alert is sent to clinic prompting follow-up by a clinician. In the case of care homes, the home receives an email reminder after 24 hrs.

ONS compliance, weight changes and $\mathrm{BMI}$ are assessed using software aligned to the "Malnutrition Universal Screening Tool" ("MUST"); if readings are outside of the pre-determined parameters, a healthcare professional is alerted, and contact is made to make changes to treatment. 


\section{Duration}

Ongoing.

100 days.

able to demonstrate significant cost efficiencies for their services, although there were indirect efficiencies for Trust 1 due to better compliance with treatment and improved time within therapeutic range or body mass index, potentially resulting in fewer emergency admissions.

The data examined here comes from a retrospective qualitative study of stakeholder experiences of implementing the Health Call system. Trust1 had substantial experience in implementing and running telemonitoring at scale using Health Call; staff possessed significant anecdotal experience and tacit corporate knowledge but did not have the resource or expertise for a rigorous analysis of this. The aim of the study was to collect, analyse, assimilate and translate this knowledge to identify generic issues and understand barriers, challenges, benefits and enablers of DEHc. We concentrate on implementations in the INR monitoring clinic and the dietetic undernutrition service because the eventual outcomes were so different; the former being adopted but the latter not being re-commissioned (despite a positive service evaluation, winning awards, and the service being successfully introduced in two other trusts). We then discuss findings in the context of the literature.

\section{Methods}

The study was undertaken by University of Cumbria in partnership with Trust 1 and funded by the Academic Health Science Network for North East and North Cumbria (AHSN-NENC). A study protocol was produced and scrutinised by the Trust Research Lead and given ethical approval as a service evaluation.

Qualitative data was collected via semi-structured interviews so as to facilitate in-depth conversations and allow interviewees to introduce issues they believed important. An established interview schedule, developed in previous evaluations of digital health projects, was used (see appendix 1). The aim was to gather the viewpoints of differently placed stakeholders including "economic" stakeholders (managers, commissioners) and "user" stakeholders (clinicians). Whilst it is important to recognise that economic stakeholders are the decision makers, the perspectives of user stakeholders are critically important in influencing adoption. Interviews were conducted with eight informants (one manager and clinicians from INR, Dietetics and Physiotherapy from Trust1, and a Clinical commissioning Group (CCG) lead). Clinical informants were selected due to their involvement with implementing Health Call in their service; the manager and commissioner were selected due to their oversight of digital implementation in Trust1. Informants gave their consent to be interviewed, all interviews were recorded, fully transcribed and then analysed thematically using NVIVO software. Initial themes were developed from the interview schedule with further themes 
added as they emerged during analysis.

\section{Findings}

Implementation of Health Call-INR was project-led by the INR service lead; being a senior grade granted a level of authority to lead change. Nevertheless, the project lead was initially sceptical that the proposed service would be appropriate or acceptable to patients; she needed to be convinced and was persuaded to participate by senior staff within the trust. Alternatively, the implementation of Health Call-Undernutrition was led by a dietician within the dietetics team. She "championed" the system, motivated by frustration with the existing pathway:

I wasn't seeing [patients] in a timely manner; I wasn't able to review them in a timely manner. There were a lot of people that I was seeing that I felt didn't really need active input at the time that I was seeing them. They might have done at a different point, but we didn't really have that flexibility within the service. Patients fitted onto a pathway, we saw them once, we saw them again in a certain period of time and we saw them again and then discharged and it didn't really matter what was happening within those periods (Undernutrition).

Health Call-INR was the first to pilot which meant implementation was more measured. There was a long lead in time and the project lead was involved from the start; accordingly, she was empowered to influence service design, ensure alignment with the prevailing pathway, and to incorporate patient safety features:

I can remember going there when we set it up, and saying, "it's got to mirror what we' re doing on clinic. We had to get the INR into the system... I wanted to have the safety questions, any bleeding symptoms, any missed doses, any change of any medication... we worked very closely on getting it to what we wanted for the clinicians (INR).

Involvement facilitated a process of engagement and of sense-making with the wider INR team which then helped in gaining clinician acceptance, and protecting clinicians' professional identities:

I always came back from a meeting saying, "They' re going to do this, they' re going to try that." Almost drip feeding [information to colleagues] instead of it being a big bang theory type of thing. [With] my junior Sister on outpatients, we would sit, mull it over and talk it through. Even though we didn't have meetings, I could pop in and say, "I think we should have these questions, what do you think?' [...] It was the clinicians giving us feedback and me going back and saying this is what we want. With it being clinician led it's gone down better (INR).

The INR lead was actively supported during implementation by a Neuro Linguistic Programming coach "She basically hand-held [clinician] through all of 
those peaks and troughs in her emotions" (Manager). Further, the technology provider dedicated a member of staff to be on site during the first week to help with queries and teething problems. The provider was quick to respond to requests for system changes: "We had teething problems, but the company was very good if we said, "That doesn't work", we'd feed back to them and then they'd change it" (INR).

However, when Health Call-Undernutrition was implemented such "support" had lessened due to reduced resources: "People have had to go away and deal with it" (Manager). Similarly with technology provider "responsiveness": "It seemed like it would take months to get any changes, or you'd give them the process and then nine months later you might get it back again" (Undernutrition). Undernutrition also faced tight SHA deadlines for completion. In addition, the dietetics department was being restructured. Dietetic managers were supportive but were also concerned not to exacerbate staff stress levels and so did not push the system. Whilst the project lead was "bought-out" to dedicate time to the implementation, this had the negative effect of colleagues perceiving Health Call as a personal project that was being imposed upon them.

Subsequently, implementation in dietetics was more complicated, less resource-intensive and done in more pressurised circumstances. There were reduced opportunities for planning and engagement with the wider dietetics team which was regrettable as the new pathway did not align with the existing one. Ultimately, the project lead struggled to "champion" the system:

I'd tried it, I'd tested it, I'd done dummy patients, I knew it inside out. When it came to using it, I had a clear idea about how to sell it to patients, to care homes ... I think we fell down in how we tried to get clinicians on board in the department. They struggled with the concept of it and how it was going to work and the impact that it was going to have on their workload. We just went scattergun with it ... I think clinicians found that quite difficult $[\ldots]$ We were also going through a departmental restructure and merging organisations. There was an awful lot going on at the same time. It was badly timed and implemented. We didn't really change pathways either, so we just expected this to clonk on to what we were already doing, and it didn't work (Undernutrition).

Consequently, Health Call-Undernutrition received a mixed response from dietetic staff; some were ostensibly enthusiastic "but then never actually used it", and others "were just anti it from the start" (Undernutrition). Moreover, of the 23 dietitians trained to use the system only ten dietitians registered patients and used the service. The lack of support within the team was very frustrating for the project lead:

If someone in your department has got an idea and it is innovative and it can change things, then you should be pursuing that. As much as I wasn't stopped, there was a certain amount of passive-aggressiveness (Undernutrition). 
The service had been designed to enable dieticians to prioritise patients experiencing changes in condition but, because alerts were coming in whilst dieticians continued with the prevailing pathway, the alerts were felt as "additional" to their normal routine:

Job plans weren't changed, so people weren't given dedicated time to deal with the alerts, deal with the patients. Often what would happen is they would have their weeks full of their normal stuff, if you like, and then they'll get this backlog of alerts and that's when it isn't working (Undernutrition).

Dieticians struggled to envisage the relative advantages and instead perceived Health Call as simply generating "more work".

Alternatively, INR staff were quick to recognise relative advantages. Crucially, clinics became more manageable:

Friday was our busy clinic and it wasn't unknown to have 140 plus in 3 hours. If it was a bank holiday, it could have been up to $170,180 \ldots$ At the end of the day, you were looking at a magnolia wall, dosing patients. Patients came in, you dosed them, and they went. [...] I walked around there yesterday and there were 50 patients on the clinic and two nurses. I laugh every time I see that because we were never like that. It's halved, three-quartered, the clinics.

Further, INR staff recognised patient benefits, mostly of convenience and savings in time and money, but significant improvements in the "time within therapeutic range" (TTR) were also noted - TTR improved by $20 \%$ for $70 \%$ of the first cohort of patients.

Notwithstanding, both INR and dietetic staff had initially expressed concerns about patients' ability to self-manage; this revealed a distrust of patients. In INR it was "Are they putting the right results in? Are they going to test when you want it?"; in dietetics there was a feeling that "patients would tell us what they thought we would want to hear, rather than what was actually happening" (Undernutrition). Staff in INR were proved wrong: "Patients are well able to look after themselves" (INR).

Alternatively, there were mixed beliefs about the benefits of Health Call within the dietetic department, with clear differences between those that used the system regularly and those that did not. Concerns about the accuracy of the monitoring information patients provided continued, as did concerns amongst nonusers that the system would result in reduced contact with patients. Significantly however, dieticians using the system felt it improved the patient/clinician relationship, facilitated prioritising of patients and, in some cases, enabled cessation of ONS far sooner than was possible under the prevailing pathway.

Moreover, pilot evaluations found Health Call to be safe, effective, and acceptable to patients. Yet the INR service was adopted, but undernutrition was not, at least not at Trust1. Ultimately, this was about funding. Both INR and Dietetics are funded through block contracts. They are paid, in advance, to deliver 
specific services in a geographical area "independent of the actual number of patients treated or the amount of activity undertaken" [9]. Consequently, once contracted they can deliver the service in whichever way they choose - within parameters of course. Commissioners believe this gives providers flexibility to deliver services in innovative ways and allows them to retain any savings made, which is seen as an incentive. Health Call-INR was not cheaper: "The cheapest way to do any service is to get all the patients to come in, to a nurse" (INR). It was comparable to the prevailing pathway however, even after allowing for the extra costs associated with self-testing (software licenses, machines, strips). But other advantages (including better functioning clinics, prioritising of patient care to those that need it and convenience to patients) aided the decision to adopt.

Matters were more complicated with undernutrition. Comparative analyses between pathways were problematic because they were so different there was a lack of comparative data: "I was presenting my data and I knew weights of people every week for three months. Try and compare that to the usual service, where... they haven't even weighed somebody" (Undernutrition). Dietetics experienced some benefit from improved caseload management and reductions in unnecessary home visits, but additional money was required for the software license and the number of service users remained the same. Consequently, efficiencies within dietetics were relatively small. Notwithstanding, efficiencies accrued elsewhere (from more appropriate prescribing of and compliance with ONS and fewer emergency admissions) remained elsewhere. The dietetic service felt the CCG ought to fund Health Call as the CCG were seeing financial benefit. The CCG argued that they were already paying for the service.

I think the way things are funded don't help... So for dietetics, we're commissioned [to] provide that service... Commissioners are saying, "well, we've paid for you already". But then we are saying, "but you' re seeing all the savings from the supplement reduction, so therefore we want to be recompensed. [And they say] "But you' re being more efficient" (Undernutrition).

In summary, there were significant differences in implementation of Health Call-INR and Undernutrition, these are summarised in Table 2. Important factors included the grade/status of the project lead; time available for planning and wider team engagement; support given to the project lead and provider responsiveness. Significant savings were not apparent for either service but the manifestation of relative advantages within INR impacted on staff acceptance of Health Call and adoption of the service. The relative advantages from Health Call-Undernutrition were less obvious to staff and managers and this impacted on acceptance.

\section{Discussion}

Most of the difficulties discussed above resonate with findings reported in other 
Table 2. Summary of findings between health call in INR and undernutrition services.

\begin{tabular}{ll}
\hline \multicolumn{1}{c}{ INR Service } & \multicolumn{1}{c}{ Undernutrition Service } \\
\hline $\begin{array}{l}\text { Lenior staff member-intensive support } \\
\text { from trust management, technology } \\
\text { provider and Neurolinguistic Therapist. }\end{array}$ & $\begin{array}{l}\text { Regular staff member-limited } \\
\text { support from trust management and } \\
\text { technology provider. }\end{array}$ \\
Development time \\
$\begin{array}{l}\text { Extended duration-long lead in time } \\
\text { for design, development, } \\
\text { and staff engagement. }\end{array}$ & $\begin{array}{l}\text { Limited duration-tight deadlines for } \\
\text { completion, resulting in short lead in } \\
\text { time for staff development/engagement } \\
\text { and pathway redesign. }\end{array}$
\end{tabular}

\section{Staff/service team engagement}

Continuous-wider team involved in service design, development and implementation.
Limited-wider team involved in training for new service but not design and development.

\section{Alignment to prevailing service pathway}

Close alignment-the new pathway mirrored the existing one.
Not aligned-the new pathway was significantly different from the existing one.

\section{IT and Technical support during implementation}

On site, in-person support from technology Off site, remote support from provider during implementation phase; technology provider quick to respond to requests for changes. technology provider; technology provider slow to respond to requests for changes.

\section{Relative advantages}

Staff perceived relative advantages to themselves from better functioning clinics and to patients from convenience and improved time within therapeutic range.
Staff did not perceive relative advantages; Health Call perceived as generating new work.

\section{Decision to adopt}

Financially comparable to existing service but with relative advantages-better functioning clinics and time within therapeutic range.
Financially comparable to existing service but additional costs for software licenses which could not be offset at service level by savings from reduced ONS and improved time within therapeutic range.

studies. Staff engagement is significant, indeed "acceptance by professional staff may be the single most important determinant of whether a new technology-supported service succeeds or fails at a local level" [3]. This was clearly the case with regards to Health Call.

Staff engagement is crucial for gaining acceptance and getting "buy-in" for TEHc. For example, staff sometimes struggle to "make sense" of e-health [10]; 
other studies report that staff are frequently unconvinced of the need for digital innovation [4] [11] [12]. Mair et al. [13] highlight the importance of providing opportunities for "sense making" wherein staff can develop shared understanding of purpose, the potential benefits, and what is expected from them; such engagement assists in gaining their "cognitive participation" or "buy-in". Ross et al. [2] suggest engagement fosters "a sense of ownership". In this scenario, Health Call-INR benefitted from a more measured approach to implementation; the project lead had status within the team and was therefore able to engage staff from the start. Alternatively, the undernutrition project lead was a regular member of the dietetics team, had a much shorter timescale for implementation and consequently, was unable to engage staff to any great extent.

The same was the case with stakeholder involvement in design, which has also been shown to help overcome staff resistance and barriers of compatibility [2] [4] [14] [15]. INR staff contributed to system design which resulted in the new service being compatible with prevailing practises; this delimited disruption during implementation. Alternatively, the rationale for Health Call-Undernutrition demanded a new pathway, but dieticians were not involved in designing this, they then struggled to adapt to the new ways of working. This is not unusual, DEHc frequently disrupts professional roles, responsibilities and tasks [2] [4] [16]. Such disruption can induce fear, dissatisfaction and uncertainty in staff, as well as hinder implementation and use [2]. Therefore, where close alignment to existing practises cannot be achieved attention to service re-design is essential, the undernutrition lead did not have the time resource or authority to action this.

In addition, restructuring of Dietetics at the time of implementation cannot have helped. Indeed, pressurised work environments produce resistance from staff due to the level of work involved in implementation [10] [12] [14] [17]. One should not underestimate the increase in workload, as Zanaboni and Wootton argue, implementing DEHc is "almost always more time and trouble than practising in the ordinary way" [12].

A significant challenge in implementation is often the technology itself [4] [15] [17] [18] [19]. Several studies have highlighted the need for technical support during roll-out [2] [4] [18] [20]; this support must be readily accessible so that clinical staff "can offload technical issues" [20]. Once again, such support was available to INR but not to undernutrition; the project lead was forever chasing the provider and the time taken to effect system changes extended.

Greenhalgh et al. [21] suggest that resistance to technological innovations is comprised of four elements, resistance to: policy reflected in the technology; sociomaterial constraints; compromised professional practice; and compromised professional relationships. Here, the technology itself did not cause resistance because it was relatively basic and interoperable with hospital systems. Compromised professional practice was not an issue either because staff continued to exercise professional judgement. However, both staff groups were initially opposed to the idea of patient self-monitoring (policy) and were concerned about 
compromised professional relationships with patients because of misgivings about their ability to self-monitor. Staff are often anxious about transferring responsibility to patients because they do "not trust patients to self-monitor and make judgements about health-related matters as effectively as professionals" [4]. Other studies highlight staff concerns about the impact of DEHc on the staff-patient relationship, which is often felt negatively [4] [22] [23] [24]. Many health professionals view face-to-face as the "gold standard" of care that should not be substituted; any change to this is perceived as threatening [25].

The status of the project leads also impacted adoption. The status of the INR lead gave her authority to instigate change. Alternatively, the project lead for undernutrition took on the role of "Digital Champion" but did not have the individual authority to initiate change. Studies have recommended the use of "digital champions" to facilitate implementation [2] [4] [15]. Such champions are effective in promoting and increasing awareness of potential benefits and in supporting staff to learn and engage with new ways of working [15]. However, the undernutrition lead struggled to champion Health Call to dieticians. Where change is desired the role of champion can be contested and established partnerships may fracture where staff reorganisation is required [4]. Wade et al. [5] found that over-reliance on a single champion can make services vulnerable; they highlight a successful project that failed due to a mixture of factors including: "loss of senior management support", "loss of interest of clinicians", "overreliance on a single champion", and "a proliferation of nay-sayers" - a situation familiar to the undernutrition lead. Strong leadership and support from commissioners, strategic managers and senior staff has also been identified as important [4] [15] [19] [20]. As evidenced here, senior level support can improve effective implementation [2] and encourage staff to see DEHc as a long-term investment [15].

Both projects struggled to demonstrate efficiencies for the respective services. But, as Zanaboni and Wootton assert "success is a relative term, not an absolute attribute" [12], whilst they suggest that successful interventions should be more efficient than the service replaced, they also acknowledge that "evidence of cost-effectiveness is a necessary but not sufficient condition for adoption". Moreover, the determinants of success (and failure) are various and therefore, for an innovation to be adopted it must show relative advantage; it must be perceived to be better than the existing alternatives [12]. Here, INR staff identified relative advantages to themselves (better functioning clinics) and to patients (convenience). On the contrary, dieticians struggled to see any advantages and simply viewed Health Call as generating "more work".

Moreover, this case study shows that success or failure is complex and results from the interaction between combinations of different factors. Greenhalgh et al. [3] have found similarly; they have developed the NASSS framework as an aid for "considering influences on the adoption, nonadoption, abandonment, spread, scale-up, and sustainability of patient-facing health and care technologies". The framework includes 16 questions in 7 domains, and answers are marked as sim- 
ple, complicated, or complex; the authors "cautiously concluded that it is complexity in multiple domains that poses the greatest challenge to scale-up, spread, and sustainability" [3]. This evidence-based, theory informed framework is designed to support those on the implementation journey; it can also be used retrospectively to help explain project failures.

We considered Health Call using NASSS and found it a useful tool and something project leads would have found helpful prior to implementation. Domain 5 was the most challenging for us; it looks at organisational aspects in relation to the sustainability of health care technologies. The trust would have performed well on all the themes, but the "simplicity" was contradicted at the service (adopter) level - especially in dietetics. Trust1 had strong capacity to innovate and actively encouraged innovation. But at dietetic service level matters became complex due to the difficulties described above. Organisational readiness was also good and supported at senior level, at service level there was little tension for change in either service; whilst support given to INR helped the project succeed, the lack of support for undernutrition meant the project lead struggled to overcome staff resistance. The INR funding decision was simple due to there being no additional costs required to sustain the service-although there would be additional costs for expansion. The funding decision for undernutrition was complex, despite evidence of financial benefit the service proved difficult to commission due to the nature of funding. Changes to service routines were necessary which might have proved complex in both services. However, this was only an issue for undernutrition where new team routines and pathways were required but not initiated and the new service was implemented alongside the existing one; this allowed staff to perceive the service as additional.

The above demonstrates that there can be a conflict between organisational leadership and service or departmental leadership. As much as organisations may encourage more or less risk taking, this needs to filter down to, and be supported at, the micro level. Health Call-INR is an example of a well lead service deployment-measured, planned, deliberate. The undernutrition service was unsuccessful and "any success was despite of the leadership" (Undernutrition).

Notwithstanding, Health Call undernutrition was re-established at Trust 1 in response to the pandemic. Indeed, within the North East of England, the pandemic prompted a big uptake of DEHc, including a drive to deploy "Health Call Digital Care Home", as well as pathways to support the remote monitoring of patients with COVID-19, heart failure, hypertension, asthma, and COPD. Nevertheless, familiar barriers and challenges to implementation and deployment remained. There were continued concerns regarding the value that using digital can provide; clinicians still perceived the move to digital as burdensome and of little relative advantage-despite anecdotal evidence of the improved patient care given at a recent feedback session.

As such, change management is crucial to improving the successful implementation of DEHc. It is not enough to simply provide equipment and then ex- 
pect change to happen. Innovation in health does not simply happen, rather successful innovation happens when change is implemented through small step, phased approaches followed by gradual roll out. Innovators, digital champions and/or project leads need to thoroughly understand prevailing practises and pathways "as is" in order to design the practises and pathways "to be". What clinicians routinely do is not always the same as pathway flow charts suggest and therefore, time must be built into pilot projects to allow for detailed understanding of practises, either to replicate them or for pathway redesign. In addition, digital services, such as Health Call, produce data that must be dealt with; a new service must include in pathway design to whom the information will go and whose responsibility it will be to act on it.

Furthermore, successful deployment is highly dependent on good leadership and the ability of project leads to take teams with them, project leads need to be supported through this process. User stakeholders also need to be supported during and post implementation; it is highly advantageous to provide technical support to users, in the form of a "help desk" for example. The process of implementation is also dependent on winning the hearts and minds of a range of stakeholders, who will be motivated by different factors. Therefore, different narratives conveying the benefits of DEHc, targeted at the different stakeholder groups (i.e., economic and user stakeholders), are needed.

\section{Conclusions}

This paper has discussed the implementation of Health Call in two services within the same trust prior to the COVID-19 pandemic. The barriers and enablers identified are well known to researchers in this field.

What is less understood are the demands made on the staff leading these implementations. There is a push for digital champions across healthcare professions; the suggestion is that any grade of staff can be one. Digital champions are undoubtedly helpful, but our findings illustrate that without senior management support the role can be frustrating and isolating.

Further, organisational support for digital innovation can be apparent but often does not trickle down to service level. Similarly, the call for digital-first solutions [1] is welcome but quite often trusts do not have the infrastructure in place to support this vision. Senior management needs to lead on both of these.

Funding systems also impact. Digital projects are often piloted with time-limited funding, but implementation takes time; measured approaches are more successful. Project leads need time to embed new projects; this would also facilitate the collection of proof of impact. Funders, commissioners and senior managers need to recognise this.

\section{Conflicts of Interest}

The authors declare no conflicts of interest regarding the publication of this paper. 


\section{References}

[1] NHS. NHS Long Term Plan. https://www.longtermplan.nhs.uk/online-version

[2] Ross, J., Stevenson, F., Lau, R. and Murray, E. (2016) Factors That Influence the Implementation of e-Health: A Systematic Review of Systematic Reviews (An Update). Implementation Science, 11, Article No. 146.

https://doi.org/10.1186/s13012-016-0510-7

[3] Greenhalgh, T., Wherton, J. and Papoutsi, C. (2017) Beyond Adoption: A New Framework for Theorizing and Evaluating Nonadoption, Abandonment, and Challenges to the Scale-Up, Spread, and Sustainability of Health and Care Technologies. Journal of Medical Internet Research, 19, e367. https://doi.org/10.2196/jmir.8775

[4] Brewster, L., Mountain, G., Wessels, B., Kelly, C. and Hawle, M. (2013) Factors Affecting Frontline Staff Acceptance of Telehealth Technologies: A Mixed-Method Systematic Review. Journal of Advanced Nursing, 70, 21-33. https://doi.org/10.1111/jan.12196

[5] Wade, V., Eliott, J., Karnon, J. and Elshaug, A.G. (2010) A Qualitative Study of Sustainability and Vulnerability in Australian Telehealth Services. Studies in Health Technology and Informatics, 161, 190-201.

[6] Zanaboni, P. and Wootton, R. (2016) Adoption of Routine Telemedicine in Norwegian Hospitals: Progress over 5 Years. BMC Health Services Research, 16, Article No. 496. https://doi.org/10.1186/s12913-016-1743-5

[7] Bidmead, E. and Marshall, A. (2020) Covid-19 and the "New Normal": Are Remote Video Consultations Here to Stay? British Medical Bulletin, 135, 16-22. https://doi.org/10.1093/bmb/ldaa025

[8] InHealthcare. https://www.inHealthcare.co.uk

[9] BMA. Models for Paying Providers. https://www.bma.org.uk/collective-voice/policy-and-research/nhs-structure-and-de livery/nhs-structures-and-integration/models-for-paying-providers/block-contracts

[10] Oconnor, S., Hanlon, P., Odonnell, C., et al. (2016) Understanding Factors Affecting Patient and Public Engagement and Recruitment to Digital Health Interventions: a Systematic Review of Qualitative Studies. BMC Medical Informatics and Decision Making, 16, 120. https://doi.org/10.1186/s12911-016-0359-3

[11] Moeckli, J., Cram, P., Cunningham, C. and Reisinger, H.S. (2013) Staff Acceptance of a Telemedicine Intensive Care Unit Program: A Qualitative Study. Journal of Critical Care, 28, 890-901. https://doi.org/10.1016/j.jcrc.2013.05.008

[12] Zanaboni, P., Wootton, R. and Zanaboni, P. (2012) Adoption of Telemedicine: From Pilot Stage to Routine Delivery. BMC Medical Informatics and Decision Making, 12, Article No. 1. https://doi.org/10.1186/1472-6947-12-1

[13] Mair, F.S., May, C., O’Donnell, C., Finch, T., Sullivan, F. and Murray, E. (2012) Factors That Promote or Inhibit the Implementation of e-Health Systems: An Explanatory Systematic Review. Bulletin of the World Health Organization, 90, 357-364. https://doi.org/10.2471/BLT.11.099424

[14] Odeh, B., Kayyali, R., Nabhani-Gebara, S. and Philip, N. (2014) Implementing a Telehealth Service: Nurses' Perceptions and Experiences. British Journal of Nursing, 23, 1133-1137. https://doi.org/10.12968/bjon.2014.23.21.1133

[15] Taylor, J., Coates, E., Brewster, L., Mountain, G., Wessels, B. and Hawley, M.S. (2015) Examining the Use of Telehealth in Community Nursing: Identifying the Factors Affecting Frontline Staff Acceptance and Telehealth Adoption. Journal of Advanced Nursing, 71, 326-337. https://doi.org/10.1111/jan.12480 
[16] Segar, J., Rogers, A., Salisbury, C. and Thomas, C. (2014) Roles and Identities in Transition: Boundaries of Work and Inter-Professional Relationships at the Interface between Telehealth and Primary Care. Health \& Social Care in the Community, 21, 606-613. https://doi.org/10.1111/hsc.12047

[17] Peddle, K. (2007) Telehealth in Context: Socio-Technical Barriers to Telehealth Use in Labrador, Canada. Computer Supported Cooperative Work, 16, 595-614. https://doi.org/10.1007/s10606-006-9030-3

[18] Lerouge, C., Garfield, M.J. and Collins, R.W. (2012) Telemedicine: Technology Mediated Service Relationship, Encounter, or Something Else. International Journal of Medical Informatics, 81, 622-636. https://doi.org/10.1016/j.ijmedinf.2012.04.001

[19] Marshall, A. and Bidmead, E. (2018) Using Telemedicine in Practice: Implications for Workforce Development. International Journal of Practice-Based Learning in Health and Social Care, 6, 111-124. https://doi.org/10.18552/ijpblhsc.v6i2.433

[20] Volpe, T., Boydell, K.M. and Pignatiello, A. (2013) Attracting Child Psychiatrists to a Televideo Consultation Service: The TeleLink Experience. International Journal of Telemedicine and Applications, 2013, Article ID: 146858.

https://doi.org/10.1155/2013/146858

[21] Greenhalgh, T., Swinglehurst, D. and Stones, R. (2014) Rethinking "Resistance" to Big IT: A Sociological Study of Why and When Healthcare Staff Do Not Use Nationally Mandated Information and Communication Technologies. Health Services and Delivery Research, 2, 1-86. https://doi.org/10.3310/hsdr02390

[22] Bidmead, E., Lie, M., Marshall, A., Robson, S.C. and Smith, V.J. (2020) Service User and Staff Acceptance of Fetal Ultrasound Telemedicine. Digital Health, 6, 1-12. https://doi.org/10.1177/2055207620925929

[23] Vuononvirta, T., Timonen, M., Keinänen-Kiukaanniemi, S., et al. (2011) The Compatibility of Telehealth with Health-Care Delivery. Journal of Telemedicine and Telecare, 17, 190-194. https://doi.org/10.1258/jtt.2010.100502

[24] Young, L., Brendan, C., Paul, S. and Cram, P. (2011) Staff Acceptance of Tele-ICU Coverage. Chest, 139, 279-288. https://doi.org/10.1378/chest.10-1795

[25] Sharma, U. and Clarke, M. (2014) Nurses' and Community Support Workers' Experience of Telehealth: A Longitudinal Case Study. BMC Health Services Research, 14, Article No. 164. https://doi.org/10.1186/1472-6963-14-164 


\section{Appendix}

\section{NENC AHSN Health Call Project \\ Interview schedule}

\section{Introduction}

We recognize that the adoption of health technology requires commitment from a range of parties and so our research is concerned to discover what this service innovation means to different stakeholders as well as how its implementation was experienced.

\section{Economic Stakeholders:}

1) Please can you tell me what motivated you to support this innovation?

2) In your opinion, how will your department/organisation benefit?

3) What evidence convinced you that the innovation was a success? And that your participation was worthwhile?

\section{All stakeholders}

1) Thinking back to when you first heard about the "Health Call [service] monitoring", what were your thoughts? What were your feelings?

2) Thinking back to before the Health Call [service] monitoring began, did you feel prepared?

3) What were your thoughts/feelings when you first started using "Health Call [service] monitoring"?

4) Now that you have been using "Health Call [service] monitoring" what are your thoughts about using it?

5) Thinking about your patients, how well have they managed the "Health Call [service] monitoring"?

6) What are the impacts for patients from using "Health Call [service] monitoring"?

7) What are the impacts for you from "Health Call [service] monitoring"?

8) What are the impacts for your organisation from "Health Call [service] monitoring"?

9) Briefly, before we close, please summarize the benefits of "Health Call [service] monitoring"?

10) What are the problems or pitfalls? What are your concerns?

11) Is there anything else you would like to add?

\section{Thank you for your time.}

